\title{
Patient-Administered Biologic and Biosimilar Filgrastim May Offer More Affordable Options for Patients with Nonmyeloid Malignancies Receiving Chemotherapy in the United States: A Budget Impact Analysis from the Payer Perspective
}

\author{
Holly Trautman, PharmD, MS; Erika Szabo, MPH, MSPharm; \\ Elizabeth James, PharmD, PhD; and Boxiong Tang, MD, PhD, MPH
}

\begin{abstract}
BACKGROUND: Granulocyte colony-stimulating factors (G-CSFs) are often administered to reduce the incidence, severity, and duration of febrile neutropenia (FN) in chemotherapy patients. Tbo-filgrastim and filgrastim-sndz represent a follow-on biologic and a biosimilar version, respectively, of the short-acting G-CSF filgrastim with comparable efficacy and safety.
\end{abstract}

OBJECTIVE: To estimate the budget impact of increasing use of patient(home-) administered tbo-filgrastim and filgrastim-sndz from a U.S. payer perspective.

METHODS: An interactive budget impact model was developed to estimate the changes in drug cost associated with projected increases in the market share of tbo-filgrastim from $5 \%$ to $10 \%$ and of filgrastim-sndz from $10 \%$ to $12 \%$ (with a corresponding decrease in filgrastim market share from $85 \%$ to $78 \%$ ) for a 1 million-member health plan among patients with nonmyeloid malignancies receiving chemotherapy with a high risk of FN. Patient self-administration at home was assumed for $20 \%$ of patients receiving short-acting G-CSF treatment; all products were purchased through the patient's pharmacy benefit and were assumed to have tier 3 formulary status with a patient copay of $\$ 54$ per prescription. Base-case data were derived from publicly available resources. The total plan budget impact was calculated using a 1-year time horizon, along with the differences in per member per month and per member per year (PMPY) costs between the current and future scenarios.

RESULTS: The effective annual per-patient drug cost to the plan totaled between $\$ 16,961$ and $\$ 27,199$, depending on dosage and packaging, for tbo-filgrastim; between $\$ 16,216$ and $\$ 26,015$ for filgrastim-sndz; and between $\$ 19,134$ and $\$ 30,663$ for filgrastim. The estimated total annual plan cost associated with patient-administered short-acting G-CSFs was $\$ 53,298,217$ (PMPY $=\$ 53.30$ ) in the current scenario and $\$ 52,828,832$ $(P M P Y=\$ 52.82)$ in the future scenario. Cost savings totaled $\$ 469,385$ $(P M P Y=\$ 0.48)$. The model was most sensitive to changes in the percentage of patients self-administering G-CSF at home and to the wholesale acquisition cost for filgrastim.

CONCLUSIONS: The effective annual plan per-patient drug costs for tbofilgrastim and filgrastim-sndz were $11 \%$ and $15 \%$ lower than filgrastim, respectively. The present analysis estimated an annual U.S. health plan cost savings approaching $\$ 0.5$ million following increases in market shares of approximately $5 \%$ for tbo-filgrastim and $2 \%$ for filgrastim-sndz.

J Manag Care Spec Pharm. 2019;25(1):94-101

Copyright $\odot 2019$, Academy of Managed Care Pharmacy. All rights reserved.

\section{What is already known about this subject}

Granulocyte colony-stimulating factors (G-CSFs) are effective at reducing the incidence, severity, and duration of febrile neutropenia. Short-acting filgrastim is one of the most widely used G-CSFs Tbo-filgrastim and filgrastim-sndz represent a follow-on biologic and a biosimilar version, respectively, of filgrastim with comparable efficacy and safety.

\section{What this study adds}

The effective annual plan per-patient drug costs for tbo-filgrastim and filgrastim-sndz were $11 \%$ and $15 \%$ lower than for filgrastim, respectively.

Switching to either tbo-filgrastim or filgrastim-sndz would decrease total annual plan costs for a 1 million-member health plan by almost $\$ 0.5$ million, with per-member cost savings of $\$ 0.04$ monthly and \$0.48 annually.

Additional cost savings may be achieved in the home administration setting with increased use of tbo-filgrastim versus other short-acting G-CSFs as a result of tbo-filgrastim's longer stability at room temperature.

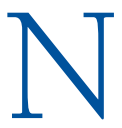
eutropenia occurs when patients experience abnormally low white blood cell counts (nadir $<1.0 \times 10^{9} / \mathrm{L}$ ) due to chemotherapy-induced myelotoxicity and is a common yet serious complication. ${ }^{1}$ Neutropenia is the primary cause of chemotherapy delays and dose reductions, potentially compromising patient outcomes, including survival and complete response rates. ${ }^{2-4}$ Of particular concern, severe neutropenia ([SN]; absolute neutrophil count $<0.5 \times 10^{9} / \mathrm{L}$ ) and febrile neutropenia ([FN]; severe neutropenia with fever) are associated with prolonged hospitalization, serious infections and the use of broad spectrum antibiotics, decreased quality of life, and increased mortality. ${ }^{5-9}$ The degree and duration of neutropenia determine the risk of infection.,10 Studies have shown that neutropenia that lasts 2 weeks is associated with a 30\% risk of serious infection and a $45 \%$ risk if neutropenia lasts 3 weeks. ${ }^{1}$ It is estimated that approximately 8 patients out of every 1,000 
receiving cancer chemotherapy will be hospitalized for $\mathrm{FN}, 5,7$ with typical mortality rates ranging from $5 \%$ to $14 \%$, and which may exceed $50 \%$ in selected high-risk populations. ${ }^{6,11,12}$ The available published cost estimates per episode of FN have varied widely, from as low as $\$ 7,100$ to more than $\$ 24,000$. $^{13-15}$

One of the primary treatment strategies to reduce the risk of $\mathrm{SN}$ and $\mathrm{FN}$ is the prophylactic use of granulocyte colonystimulating factor (G-CSF). G-CSF is a biological growth factor that supports the proliferation, differentiation, and activation of hematopoietic cells. ${ }^{5,8}$ Practice guidelines in the United States and Europe support the use of G-CSFs as primary prophylaxis after chemotherapy when the risk of $\mathrm{FN}$ is $>20 \%{ }^{1,16}$ Treatment with G-CSFs is associated with a shorter duration of neutropenia, reduced risk of FN, shorter FN-related hospitalization, and lower mortality rate due to infection. ${ }^{9,17,18}$ In addition, G-CSFs are associated with increased probability of receiving full doses of chemotherapy, ${ }^{17,19-21}$ as well as allowing for the use of highly myelosuppressive dose-dense regimens at shorter intervals than would be possible without G-CSF support. ${ }^{17,22}$

G-CSFs currently available in the United States include short-acting filgrastim (Neupogen, Amgen), tbo-filgrastim (Granix, Teva Pharmaceutical Industries), and filgrastimsndz (Zarxio, Sandoz), as well as long-acting pegfilgrastim (Neulasta, Amgen). ${ }^{23-26}$ Filgrastim is administered subcutaneously or intravenously once daily for up to 14 days or until the patient's absolute neutrophil count has reached $10,000 / \mathrm{mm}^{3}$ following its chemotherapy-induced nadir. ${ }^{25}$ Previous clinical trials have indicated that 8-14 days of filgrastim produce the most optimal results, ${ }^{27-32}$ with 11 injections as the average. ${ }^{18,33}$ However, in clinical practice, the average duration of filgrastim prophylaxis falls short of 11 days, with estimates from realworld observational studies ranging from 4.8 to 6.4 days. ${ }^{34-36}$ In another large observational study of U.S. health care claims, patients receiving fewer than 7 days of injections had a significantly higher risk of hospitalization than patients receiving 7 days or more of injections. ${ }^{37}$

Tbo-filgrastim, first approved in 2008 in the European Union as a biosimilar and subsequently approved by the U.S. Food and Drug Administration (FDA) in 2012 as a biologic, demonstrated bioequivalence to filgrastim in 2 phase 1 randomized cross-over trials of healthy volunteers. ${ }^{38,39}$ Tbofilgrastim has also demonstrated equivalent efficacy to filgrastim in reducing the duration of $\mathrm{SN}$ and the incidence of FN in patients with breast cancer, lung cancer, or non-Hodgkin lymphoma treated with myelosuppressive chemotherapy. $24,40-42$ Furthermore, tbo-filgrastim's safety was evaluated in the same 3 clinical studies composed of 680 adults who received myelosuppressive chemotherapy; the adverse event profile was similar between tbo-filgrastim and filgrastim with bone pain as the most common side effect. ${ }^{40-42}$ Filgrastim-sndz was approved in 2015 as the first product under the FDA's biosimilar regulatory pathway and is, therefore, deemed to be highly similar to filgrastim. ${ }^{26}$ Recent retrospective claims analyses have reported statistically similar FN incidences for patients treated with filgrastim-sndz and those treated with filgrastim. . $3,44^{4}$

A budgetary impact model was developed to estimate the financial effect associated with increased use of these newer, clinically comparable, short-acting G-CSFs when administered by patients at home. This type of economic analysis is critical for payers to fully understand what the potential net cost of adoption of new health technology will be. The objective of this model was to estimate the annual economic cost of increasing utilization of tbo-filgrastim and filgrastim-sndz as a patient- (home-) administered treatment option for patients with nonmyeloid malignancies undergoing myelosuppressive chemotherapy from a U.S. payer perspective.

\section{Methods}

\section{Model Structure}

An interactive economic model was constructed in Microsoft Excel 2016 (Microsoft Corp., Redmond, WA) to estimate the changes in costs due to an increase in the use of patientadministered tbo-filgrastim and filgrastim-sndz treatment from the perspective of a 1 million-member health plan in the United States. It was developed in accordance with the current International Society of Pharmacoeconomics and Outcomes Research Budget Impact Analysis Principles of Good Practice. ${ }^{45}$ The model used a base-case set of inputs derived from publicly available resources, that is, published peer-reviewed scientific literature, individual product FDA-approved labeling, wholesale acquisition cost (WAC), and National Drug Code (NDC)-level utilization data. No patient-level identifiable data were used.

Drug costs were combined with population and product market share information to calculate the total budgetary impact associated with increasing use of patient-administered tbo-filgrastim and filgrastim-sndz in the future. A 1-year time horizon was used to reflect the short-term nature of the treatment and budgetary cycle, and costs were not discounted. The total annual budget impact was calculated for the entire hypothetical health plan, along with differences in per member per month (PMPM) and per member per year (PMPY) costs between the current and future scenarios. A scenario analysis evaluated the budget impact including syringe replacement, and one-way sensitivity analyses were conducted.

\section{Eligible Population}

The budgetary impact model started with a hypothetical 1 million-member U.S. health plan, which was then narrowed down to include only patients with nonmyeloid malignancies treated with myelosuppressive chemotherapy and patientadministered short-acting G-CSFs. Population estimates are summarized in Table 1. The proportion of patients with 
Patient-Administered Biologic and Biosimilar Filgrastim May Offer More Affordable Options for Patients with Nonmyeloid Malignancies Receiving Chemotherapy in the United States: A Budget Impact Analysis from the Payer Perspective

\begin{tabular}{|c|c|c|c|}
\hline $\begin{array}{l}\text { Pop } \\
\text { with } \\
\text { with } \\
\text { and } \\
\text { G-C. }\end{array}$ & \multicolumn{3}{|c|}{$\begin{array}{l}\text { Population Estimates for Eligible Patients } \\
\text { with Nonmyeloid Malignancies Treated } \\
\text { with Myelosuppressive Chemotherapy } \\
\text { and Patient-Administered Short-Acting } \\
\text { G-CSFs }\end{array}$} \\
\hline Parameter & $\begin{array}{c}\text { Estimated } \\
\text { Value, \% }\end{array}$ & $\begin{array}{c}\text { Eligible } \\
\text { Population, } \mathrm{n}\end{array}$ & Source/References \\
\hline Health plan members & 100.0 & $1,000,000$ & Assumption \\
\hline $\begin{array}{l}\text { Prevalence of nonmyeloid } \\
\text { malignancies }\end{array}$ & 4.3 & 43,000 & $\begin{array}{l}\text { U.S. Census } 46 \\
\text { SEER }^{47}\end{array}$ \\
\hline $\begin{array}{l}\text { Treated with myelo- } \\
\text { suppressive chemotherapy }\end{array}$ & 80.0 & 34,400 & $\begin{array}{l}\text { Culacova et al. } 49 \\
\text { Crawford et al. }{ }^{61}\end{array}$ \\
\hline Using any G-CSF & 45.0 & 15,480 & \begin{tabular}{|c|} 
Culacova et al. 49 \\
Denduluri et al..$^{50}$ \\
\end{tabular} \\
\hline Using short-acting G-CSF & 70.0 & 10,836 & Griffiths et al. 48 \\
\hline $\begin{array}{l}\text { atients self-administering } \\
\text { hort-acting G-CSF }\end{array}$ & 20.0 & 2,167 & Assumption \\
\hline
\end{tabular}

G-CSF = granulocyte colony-stimulating factor; SEER=Surveillance, Epidemiology, and End Results Program.

nonmyeloid malignancies was calculated by subtracting the number of cases of leukemia and myeloma from the number of cases of cancer (all sites combined) from the Surveillance, Epidemiology, and End Results database and dividing by the total U.S. population from the 2013 U.S. Census, resulting in a prevalence of $4.3 \% .{ }^{46,47}$ The default value for the proportion of patients with nonmyeloid malignancies treated with myelosuppressive chemotherapy was set at $80 \%$ based on rates observed in the literature. ${ }^{48}$ The proportion of patients undergoing myelosuppressive chemotherapy treatment estimated to be using any G-CSF (45\%) was based on use reported in the literature for similar populations of patients in the United States. ${ }^{49,50}$ The proportion of these patients estimated to be using short-acting G-CSF products was set at 70\% based on a recent Canadian study evaluating short-acting versus longacting G-CSF use during treatment for a range of different cancers ${ }^{51}$ Finally, it was assumed that $20 \%$ of patients receiving short-acting G-CSF treatment would self-administer at home.

\section{Market Share}

Marketplace dynamics are extremely important to budgetary impact models in terms of existing product use and the effect of changing the product mix in the future. Current market share distributions of tbo-filgrastim, filgrastim, and filgrastim-sndz were based on IMS Health NDC-level sales data from October 2015 to March 2016 and represent the aggregate U.S. payer marketplace. For short-acting G-CSF products administered at home, the model assumed a $4.9 \%$ market share for tbo-filgrastim, an $84.7 \%$ market share for filgrastim, and a 10.4\% market share for filgrastim-sndz. The model projected a conservative future 5\% increase in market share for tbo-filgrastim (to 9.9\%) and a future $2 \%$ increase in market share for filgrastim-sndz

\begin{tabular}{|c|c|}
\hline Parameter & Cost per Dose Package, $\$$ \\
\hline Tbo-filgrastim 300 mcg PFS & $1,440.40^{a, 52}$ \\
\hline Tbo-filgrastim 480 mcg PFS & $2,293.55^{a, 52}$ \\
\hline Filgrastim 300 mcg PFS with USNG & $3,243.00^{b, 52}$ \\
\hline Filgrastim 480 mcg PFS with USNG & $5,164.50^{\mathrm{b}, 52}$ \\
\hline Filgrastim-sndz 300 mcg PFS with USPNG & $2,756.60^{\mathrm{b}, 52}$ \\
\hline Filgrastim-sndz 480 mcg PFS with USPNG & $4,389.80^{\mathrm{b}, 52}$ \\
\hline Tier 3 patient copay & $54.00^{c, 53}$ \\
\hline \multicolumn{2}{|c|}{$\begin{array}{l}\text { aCost per 5-dose package. } \\
\text { bCost per 10-dose package. } \\
\text { cCost per cycle. } \\
\text { filgrastim = granulocyte colony-stimulating factor; filgrastim-sndz= biosimilar } \\
\text { of short-acting G-CSF filgrastim; PFS = prefilled syringe; tbo-filgrastim = follow- } \\
\text { on biologic of short-acting G-CSF filgrastim; USNG=UltraSafe Needle Guard; } \\
\text { USPNG = UltraSafe Passive Needle Guard. }\end{array}$} \\
\hline
\end{tabular}

(to $12.4 \%$ ). The increased share of tbo-filgrastim represents that of a lower-priced, follow-on biologic agent in the drug class, while the increased use of filgrastim-sndz reflects a continued but less aggressive uptake of a filgrastim biosimilar with an established larger market share than the follow-on biologic. The resultant decline in filgrastim market share from $84.7 \%$ to $77.7 \%$ assumed that the lost filgrastim utilization is replaced by both tbo-filgrastim and filgrastim-sndz. It was assumed that tbo-filgrastim syringes with safety needle guards would not be dispensed by pharmacies to patients based on recommendations in product labeling; therefore, no market share was allocated to these products. Finally, an assumption was made that filgrastim vials were not to be used for self-administration; therefore, current and future market share values were set at $0 \%$.

\section{Costs}

Per-patient drug costs were based on the dosing in the U.S. prescribing information ( $5 \mathrm{mcg}$ per $\mathrm{kg}$ per day) for each product $^{24-26}$ and the utilization per product according to IMS Health sales data. The default value for the number of days per cycle (i.e., 10 days) was based on utilization from the tbo-filgrastim phase 3 studies $^{40-42}$; the number of G-CSF cycles per year was the maximum number of chemotherapy cycles allowed in 2 of the tbo-filgrastim phase 3 studies. ${ }^{41,42}$ When short-acting G-CSFs are self-administered by a patient at home, patient health care coverage adjudication occurs through the pharmacy benefit; therefore, drug costs in the model represented WAC, based on RED BOOK Online, June 2016 (Table 2). ${ }^{52}$ All products were assumed to have tier 3 formulary status, with an associated patient copay amount of $\$ 54.00$ per 30 -day prescriptions based on the 2015 Kaiser Family Foundation and Health Research and Educational Trust employee-sponsored health benefits survey. ${ }^{53}$ Additional syringe replacement doses may occur over the course of a year due to wastage from 
Patient-Administered Biologic and Biosimilar Filgrastim May Offer More Affordable Options for Patients with Nonmyeloid Malignancies Receiving Chemotherapy in the United States: A Budget Impact Analysis from the Payer Perspective

\section{FIGURE 1 One-Way Sensitivity Analyses Based on Total Annual Plan Costs for the Future Scenario}

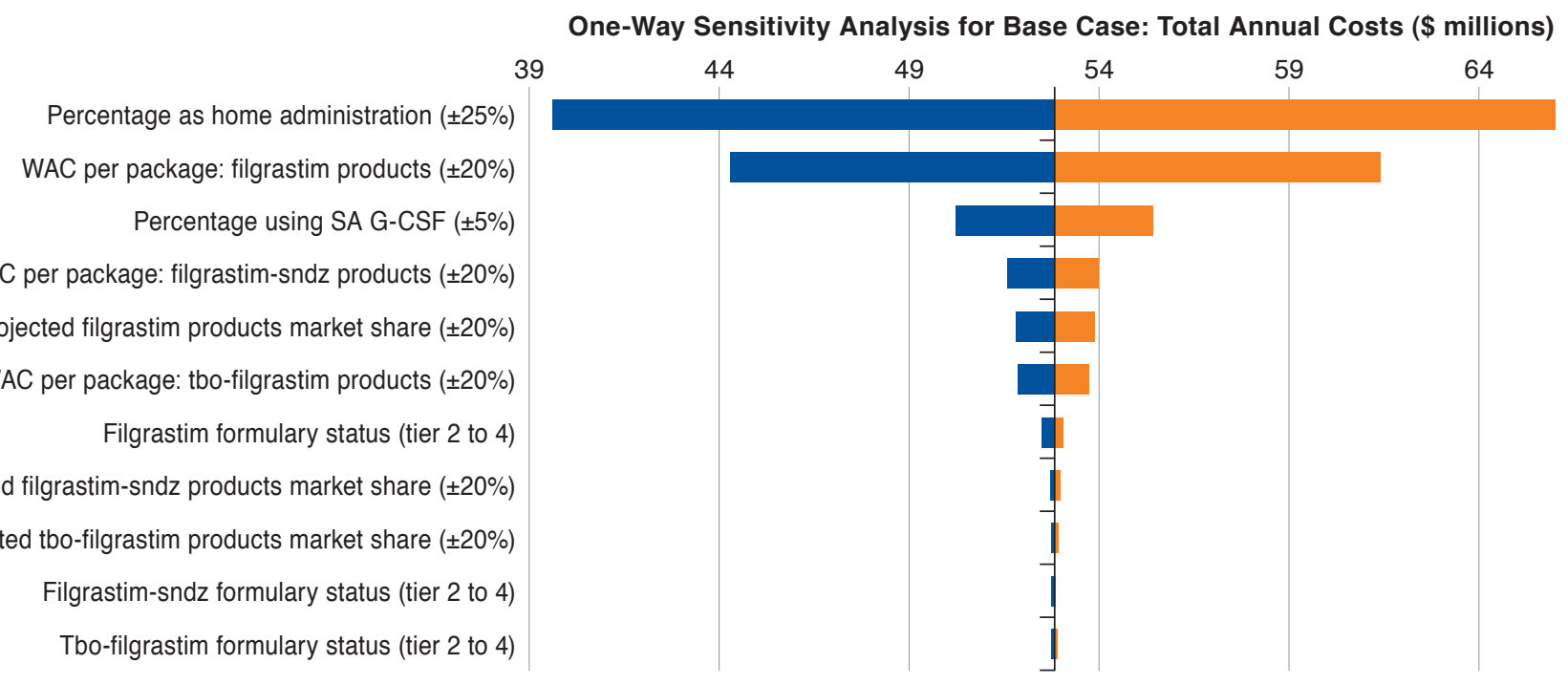

Total Plan Cost by Decreasing Parameter Total Plan Cost by Increasing Parameter

filgrastim-sndz= biosimilar of short-acting G-CSF filgrastim; G-CSF= granulocyte colony-stimulating factor; SA=sensitivity analysis; tbo-filgrastim = follow-on biologic of short-acting G-CSF filgrastim; WAC = wholesale acquisition cost.

expiration of products, resulting from inadvertent storage at room temperature beyond the stability of the product, according to respective product prescribing information; however, no syringe replacement was included in the base case.

\section{Model Outcomes}

The budgetary impact analysis estimated the costs associated with changing treatment patterns of newer, short-acting G-CSFs when self-administered by patients at home. The total annual budget impact was calculated for the target health plan, along with differences in PMPM and PMPY costs between the current and future scenarios. The population eligible for treatment was divided into product-level treatment groups based on current and future market share distribution. Annual, effective, per-patient drug costs were applied to each market segment to sum the total effective plan expenditures in the current and future scenarios. PMPY and PMPM values were calculated using the assumed 1 million plan members.

\section{Scenario and Sensitivity Analyses}

Tbo-filgrastim syringes can be stored at room temperature for up to 5 days, while filgrastim and filgrastim-sndz syringes can be stored at room temperature for up to 24 hours per respective product FDA-approved prescribing information..$^{24-26} \mathrm{~A}$ scenario analysis was conducted evaluating annual syringe replacement rates of $1 \%$ for tbo-filgrastilm and 5\% for filgrastim and filgrastim-sndz in order to estimate the budgetary impact of real-world utilization where product may be inadvertently left at room temperature by patients. Additionally, a series of oneway sensitivity analyses (SA) were conducted on the base-case results to test the effect of changing specific input parameter values or model assumptions on the results. The SA varied the following parameters: percentage of patients using short-acting G-CSF; WAC per package for tbo-filgrastim, filgrastim, and filgrastim-sndz; future market share for tbo-filgrastim, filgrastim, and filgrastim-sndz; and percentage of short-acting G-CSF self-administered at home. Also, the formulary tier status was varied in the SA (tier 2 patient copay $=\$ 31.00$ per cycle; tier 4 patient copay $=\$ 93.00$ per cycle).${ }^{50} \mathrm{SA}$ results were reported as a tornado diagram (Figure 1).

\section{Results}

Based on the use of 60 doses per year (10 days per cycle and 6 cycles per year), the annual effective plan per-patient drug cost totaled $\$ 16,961$ for tbo-filgrastim $300 \mathrm{mcg}$ syringes and $\$ 27,199$ for tbo-filgrastim $480 \mathrm{mcg}$ syringes; $\$ 16,216$ for filgrastim-sndz $300 \mathrm{mcg}$ syringes and $\$ 26,015$ for filgrastim-sndz $480 \mathrm{mcg}$ syringes; and $\$ 19,134$ for filgrastim $300 \mathrm{mcg}$ syringes and $\$ 30,663$ for filgrastim $480 \mathrm{mcg}$ syringes.

\section{Base-Case Budgetary Impact}

Base-case results represent short-acting G-CSF annual health plan costs and include drug costs, with available dosages and 
Patient-Administered Biologic and Biosimilar Filgrastim May Offer More Affordable Options for Patients with Nonmyeloid Malignancies Receiving Chemotherapy in the United States: A Budget Impact Analysis from the Payer Perspective

\section{TABLE 3 Costs Associated with Treating Chemotherapy Patients with Patient-Administered Short-Acting G-CSFs (Model Estimated Outputs)}

\begin{tabular}{|c|c|c|c|}
\hline $\begin{array}{l}\text { Short-Acting G-CSF } \\
\text { Product }\end{array}$ & $\begin{array}{c}\text { Current Scenario Total Annual Plan } \\
\text { Cost (PMPM/PMPY) }\end{array}$ & $\begin{array}{c}\text { Future Scenario Total Annual Plan Cost } \\
\text { (PMPM/PMPY) }\end{array}$ & $\begin{array}{c}\text { Difference in Total Annual Plan Cost } \\
\text { (PMPM/PMPY) }\end{array}$ \\
\hline Tbo-filgrastim & $2,311,211.00$ & $4,703,546.00$ & $2,392,335.00$ \\
\hline Filgrastim & $46,037,202.00$ & $42,260,349.00$ & $-3,776,853.00 \quad(-0.32 /-3.78)$ \\
\hline Filgrastim-sndz & $4,949,804.00$ & $5,864,937.00$ & $915,133.00 \quad(0.08 / 0.91)$ \\
\hline Total & $53,298,217.00 \quad(4.44 / 53.30)$ & $52,828,832.00 \quad(4.40 / 52.82)$ & $-469,385.00 \quad(-0.04 /-0.48)$ \\
\hline
\end{tabular}

Note: PMPM and PMPY values may be slightly different due to calculation rounding

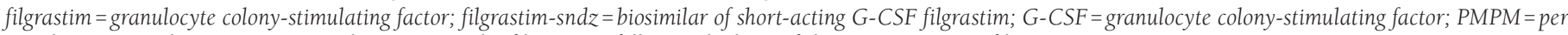
member per month; PMPY=per member per year; tbo-filgrastim=follow-on biologic of short-acting G-CSF filgrastim.

packaging aggregated by product. As shown in Table 3, the base-case budgetary impact analysis estimated that the total annual plan cost in the current scenario was $\$ 53,298,217$ for a 1 million-member health plan. Of this, $\$ 2,311,211$ was attributed to tbo-filgrastim; $\$ 46,037,202$ to filgrastim; and $\$ 4,949,804$ to filgrastim-sndz. With an increase in market share for tbo-filgrastim (5\%) and filgrastim-sndz (2\%), along with a corresponding decrease in market share for filgrastim, the estimated total annual plan cost was reduced to $\$ 52,828,832$ ( $\$ 4,703,546$ for tbo-filgrastim; $\$ 42,260,349$ for filgrastim; and $\$ 5,864,937$ for filgrastim-sndz). A total annual plan cost savings of $\$ 469,385$ was estimated. Cost savings per member between the current and future scenarios were estimated at \$0.04 PMPM and \$0.48 PMPY.

\section{Scenario and Sensitivity Analyses}

Based on the scenario analysis that included additional syringe replacement (estimated annual syringe replacement rates of $1 \%$ for tbo-filgrastim, 5\% for filgrastim, and filgrastim-sndz based on FDA-approved product labeling), the annual effective plan per-patient drug cost totaled $\$ 17,249$ for tbo-filgrastim $300 \mathrm{mcg}$ syringes and $\$ 27,657$ for tbo-filgrastim $480 \mathrm{mcg}$ syringes; $\$ 17,043$ for filgrastim-sndz $300 \mathrm{mcg}$ syringes and $\$ 27,332$ for filgrastim-sndz $480 \mathrm{mcg}$ syringes; and $\$ 20,107$ for filgrastim $300 \mathrm{mcg}$ syringes and $\$ 32,212$ for filgrastim $480 \mathrm{mcg}$ syringes. Based on national utilization patterns among products by strength, the estimated total annual plan cost associated with short-acting G-CSFs was \$55,920,046 (\$4.66 PMPM and \$55.92 PMPY) in the current scenario and $\$ 55,346,277$ (\$4.61 PMPM and \$55.34 PMPY) in the future scenario. Cost savings totaled $\$ 573,769$ (\$0.05 PMPM and $\$ 0.58$ PMPY).

The results of the one-way SA are shown as a tornado diagram in Figure 1. The model was most sensitive to changes in the percentage of patients self-administering G-CSF at home and to changes in the WAC for filgrastim. When the number of patients home-administering G-CSF was increased to 2,709 patients (a 25\% increase), total annual plan costs for the future scenario increased from $\$ 52,828,832$ to $\$ 66,042,135$; whereas, a 25\% reduction in the number of patients home-administering G-CSF (a decrease to 1,625 patients) was associated with a decrease to $\$ 39,615,529$. When the aggregated filgrastim WAC per package was increased by $20 \%$, total annual plan costs for the future scenario increased to $\$ 61,390,009$, while a $20 \%$ decrease in aggregated filgrastim WAC per package was associated with a decrease to $\$ 44,267,655$.

\section{Discussion}

Among economic modeling approaches, cost-effectiveness analyses are used to compare alternative health care strategies from a broad societal perspective and may include a wide range of associated health benefits (e.g., productivity, follow-up visits with physicians, and disease progression). In contrast, budgetary impact analyses examine the financial impact of new treatments or shifting existing treatment patterns in a specific health care setting or system, more directly addressing the question of affordability. Budgetary impact analyses are, therefore, an important method for comprehensive economic assessment, providing additional insight beyond cost-effectiveness to help decision makers determine how best to allocate resources in a given year. ${ }^{45}$

The current model used the perspective of a 1 million-member U.S. health plan to estimate the budgetary impact associated with increasing the patient- (home-) administered utilization of the newer short-acting G-CSF products, tbo-filgrastim and filgrastim-sndz, for eligble patients with nonmyeloid malignancies undergoing myelosuppressive chemotherapy. The analysis focused on home administration of G-CSFs given the presumed lower burden on patients and health plans with patient-administered use. The eligible population for the model comprised patients with nonmyeloid malignancies undergoing chemotherapy, the common indication for all 3 products included. ${ }^{24-26}$ Base-case results projected a total plan cost savings approaching $\$ 0.5$ million per year (PMPM savings $=\$ 0.04$ and PMPY savings $=\$ 0.48$ ) following an increase of market share by $5 \%$ for tbo-filgrastim and $2 \%$ for filgrastim-sndz (with a simultaneous $7 \%$ decrease in filgrastim market share). The 
effective annual plan per-patient drug costs for tbo-filgrastim and filgrastim-sndz were $11 \%$ and $15 \%$ lower than filgrastim, respectively.

Because the size of the treated population drives the overall cost of treatment, it was predictable that the base-case results were most sensitive to changes in the percentage of patients self-administering G-CSF at home. Given the base-case values, the larger the proportion of patients administering therapy at home, the larger the savings. By varying the proportion of selfadministering patients at home by $25 \%$ of the base-case value, the total annual plan costs for the future scenario ranged from $\$ 39,615,529$ to $\$ 66,042,135$. However, it is important to note that any changes in plan costs associated with a larger number of patients self-administering G-CSF would be largely offset by reduced costs associated with the smaller number of patients undergoing chemotherapy who would receive their short-acting G-CSF treatment directly from a health care provider in an office or other outpatient setting. The model was also sensitive to potential changes in the price of filgrastim.

The base-case model did not include any syringe replacement due to wastage from inadvertent storage at room temperature beyond the stability of each product. However, it is reasonable that some syringe replacement doses may be required when products are administered at home. As there are differences in thermostability between the short-acting G-CSF products, reflected in the storage requirements and patient information in their respective FDA-approved labeling, a scenario analysis that incorporated syringe replacement rates was included..$^{24-26}$ Replacement rates were estimated according to these labeled storage requirements. The scenario analysis estimated that the annual plan per-patient drug cost for tbo-filgrastim and filgrastim-sndz was 14\%-15\% lower than for filgrastim, with an annual plan cost savings in excess of $\$ 0.5$ million (a $\$ 104,384$ greater cost savings over the base-case model results). The current Handbook on Injectable Drugs indicates filgrastim may be thermostable beyond 24 hours, despite the FDA label stating 24-hour stability. ${ }^{54}$ While a longer room temperature stability could affect the replacement rate for filgrastim, the resulting economic impact, that is, potential savings to the plan, would be juxtaposed with filgrastim's higher acquisition cost.

G-CSFs are well established for reducing the risk, severity, and duration of FN, but due to historically high costs, they are not used in all appropriate patients receiving myelosuppressive chemotherapy. ${ }^{55}$ Research has also shown inconsistency in prescribing patterns leading to over- or underuse of G-CSFs. ${ }^{56,57}$ Several strategies to improve the cost-effectiveness of G-CSF use have been identified, including selective use in certain populations at increased risk for neutropenia (e.g., older patients, patients with abnormal hepatic or renal function, patients receiving high-dose chemotherapy, or patients with prior FN). ${ }^{55,58-60}$ Nonetheless, acquisition costs of G-CSFs remain a barrier, and more financially reasonable options would be beneficial for health care decision makers when evaluating different strategies for the prophylactic treatment of neutropenia. This is especially true with the availability of newer, shortacting G-CSFs that have similar efficacy and safety as filgrastim and continue to offer the flexibility to be self-administered by patients at home.

\section{Limitations}

As with any budgetary impact model, estimated results based on future product market share should be interpreted cautiously. This analysis did not explicitly evaluate the efficacy or safety of the G-CSF products, nor did it take into consideration the resulting economic impact of clinical outcomes. However, since tbo-filgrastim has previously demonstrated comparable efficacy and safety to filgrastim, and filgrastim-sndz received FDA approval as a filgrastim biosimilar, this lack of information is not expected to affect the model results or conclusions.

The patient population was limited to adults with nonmyeloid malignancies undergoing chemotherapy with a clinically significant incidence of FN. This is the indication that all included products have in common. ${ }^{24-26}$ While drug coverage policies vary from payer to payer, the model represents an aggregate U.S. health plan and does not consider productlevel utilization rates, that is, market share, based on individual payer prior authorization requirements and pharmacy and therapeutics committee recommendations. The health plan-specific recommended products and prior authorization requirements may result in differences in budget impact by way of varied market share in the current and future scenarios.

Furthermore, the administration and drug cost estimates used to populate this model were based on publicly available sources and could be expected to vary across specific health plans. Specifically, while manufacturer rebates affect budgetary expenditures within drug classes, these data are proprietary and unique to a specific health plan and so were not included in the base-case analysis. Payers must also consider on a contractual level the cost absorbed by a prior authorization process and any associated claims processing fees in the context of single prescription savings.

Finally, one-way SAs reflect a single variable effect on model results. However, it is possible a change in 1 variable in the marketplace (such as a reduction in WAC) may affect another variable (such as subsequent reductions in WACs for competitor products).

\section{Conclusions}

Tbo-filgrastim and filgrastim-sndz represent a follow-on biologic and a biosimilar version, respectively, of the short-acting G-CSF filgrastim and are associated with lower acquisition costs than filgrastim. An interactive budgetary impact model was developed to estimate, from the perspective of 


\section{Patient-Administered Biologic and Biosimilar Filgrastim May Offer More Affordable Options for Patients with Nonmyeloid Malignancies Receiving Chemotherapy in the United States: A Budget Impact Analysis from the Payer Perspective}

a 1 million-member U.S. health plan, the economic impact of increasing the patient- (home-) administered use of tbofilgrastim and filgrastim-sndz, while decreasing use of filgrastim. The effective annual plan per-patient drug costs for tbo-filgrastim and filgrastim-sndz were $11 \%$ and $15 \%$ lower than filgrastim, respectively. Based on a hypothetical increase of market share by approximately 5\% for tbo-filgrastim and $2 \%$ for filgrastim-sndz, total annual plan costs would decrease by almost $\$ 0.5$ million, with per-member cost savings of $\$ 0.04$ monthly and $\$ 0.48$ annually. A scenario analysis that included additional syringe replacement due to wastage estimated a moderate improvement in cost savings over the basecase model. This analysis suggests that concomitantly increasing the use of tbo-filgrastim and filgrastim-sndz and decreasing the use of filgrastim by patients who self-administer short-acting G-CSFs may offer a more affordable option for U.S. payers.

\section{Authors}

HOLLY TRAUTMAN, PharmD, MS, and ELIZABETH JAMES, PharmD, PhD, Aventine Consulting, Marblehead, Massachusetts. ERIKA SZABO, MPH, MSPharm, and BOXIONG TANG, MD, $\mathrm{PhD}, \mathrm{MPH}$, Teva Pharmaceuticals, Frazer, Pennsylvania.

AUTHOR CORRESPONDENCE: Erika Szabo, MPH, MSPharm, Teva Pharmaceuticals, 41 Moores Rd., Malvern, PA 19335.

Tel.: 610-727-3285; E-mail: Erika.Szabo@tevapharm.com.

\section{DISCLOSURES}

This study was sponsored by Teva Branded Pharmaceutical Products R \& D, which participated in the study design, data interpretation and analysis, the writing of the report, and the decision to submit. Aventine Consulting received consulting fees from Teva Pharmaceuticals and developed the cost model and provided data analysis support. Trautman and James are employed by Aventine Consulting. Szabo and Tang are employed by Teva Pharmaceuticals.

\section{ACKNOWLEDGMENTS}

Medical writing assistance was provided by Jason Allaire, $\mathrm{PhD}$, of Generativity Solutions Group and was funded by Teva Branded Pharmaceutical Products $\mathrm{R} \& \mathrm{D}$.

\section{REFERENCES}

1. Crawford J, Armitage J, Balducci L, et al. Myeloid growth factors. J Natl Compr Canc Netw. 2013;11(10):1266-90.

2. Lyman GH, Dale DC, Crawford J. Incidence and predictors of low doseintensity in adjuvant breast cancer chemotherapy: a nationwide study of community practices. J Clin Oncol. 2003;21(24):4524-31.

3. Lyman GH, Kuderer N, Greene J, Balducci L. The economics of febrile neutropenia: implications for the use of colony-stimulating factors. Eur J Cancer. 1998;34(12):1857-64.

4. Webster J, Lyman GH. Use of G-CSF to sustain dose intensity in breast cancer patients receiving adjuvant chemotherapy: a pilot study. Cancer Control. 1996;3(6):519-23.
5. Bennett CL, Djulbegovic B, Norris LB, Armitage JO. Colony-stimulating factors for febrile neutropenia during cancer therapy. New Engl J Med. 2013;368(12):1131-39.

6. Kuderer NM, Dale DC, Crawford J, Cosler LE, Lyman GH. Mortality, morbidity, and cost associated with febrile neutropenia in adult cancer patients. Cancer. 2006;106(10):2258-66.

7. Caggiano V, Weiss RV, Rickert TS, Linde-Zwirble WT. Incidence, cost, and mortality of neutropenia hospitalization associated with chemotherapy. Cancer. 2005;103(9):1916-24

8. Aapro MS, Bohlius J, Cameron DA, et al. 2010 update of EORTC guidelines for the use of granulocyte-colony stimulating factor to reduce the incidence of chemotherapy-induced febrile neutropenia in adult patients with lymphoproliferative disorders and solid tumours. Eur J Cancer. 2011;47(1):8-32.

9. Lyman GH, Dale DC, Culakova E, et al. The impact of the granulocyte colony-stimulating factor on chemotherapy dose intensity and cancer survival: a systematic review and meta-analysis of randomized controlled trials. Ann Oncol. 2013;24(10):2475-84.

10. Crawford J, Dale DC, Lyman GH. Chemotherapy-induced neutropenia: risks, consequences, and new directions for its management. Cancer. 2004;100(2):228-37.

11. Hirsch BR, Lyman GH. Pharmacoeconomics of the myeloid growth factors: a critical and systematic review. Pharmacoeconomics. 2012;30(6):497-511. 12. Schilling MB, Parks C, Deeter RG. Costs and outcomes associated with hospitalized cancer patients with neutropenic complications: a retrospective study. Exp Ther Med. 2011;2(5):859-66.

13. Fust K, Li X, Maschio M, et al. Cost-effectiveness analysis of prophylaxis treatment strategies to reduce the incidence of febrile neutropenia in patients with early-stage breast cancer or non-Hodgkin lymphoma. Pharmacoeconomics. 2017;35(4):425-38.

14. Fust K, Parthan A, Maschio M, et al. Granulocyte colony-stimulating factors in the prevention of febrile neutropenia: review of cost-effectiveness models. Expert Rev Pharmacoecon Outcomes Res. 2017;17(1):39-52.

15. Tai E, Guy GP, Dunbar A, Richardson LC. Cost of cancer-related neutropenia or fever hospitalizations, United States, 2012. J Oncol Prac. 2017;13(6):e552-61.

16. Klastersky J, de Naurois J, Rolston K, et al. Management of febrile neutropaenia: ESMO Clinical Practice Guidelines. Ann Oncol. 2016;27 (Suppl 5):vll1-18

17. Kuderer NM, Dale DC, Crawford J, Lyman GH. Impact of primary prophylaxis with granulocyte colony-stimulating factor on febrile neutropenia and mortality in adult cancer patients receiving chemotherapy: a systematic review. J Clin Oncol. 2007;25(21):3158-67.

18. Cooper KL, Madan J, Whyte S, Stevenson MD, Akehurst RL. Granulocyte colony-stimulating factors for febrile neutropenia prophylaxis following chemotherapy: systematic review and meta-analysis. BMC Cancer. 2011;11:404.

19. Almenar Cubells D, Bosch Roig C, Jimenez Orozco E, et al. Effectiveness of daily versus non-daily granulocyte colony-stimulating factors in patients with solid tumours undergoing chemotherapy: a multivariate analysis of data from current practice. Eur J Cancer Care. 2013;22(3):400-12.

20. Shayne M, Crawford J, Dale DC, Culakova E, Lyman GH; ANC Study Group. Predictors of reduced dose intensity in patients with early-stage breast cancer receiving adjuvant chemotherapy. Breast Cancer Res Treat. 2006;100(3):255-62.

21. Lyman GH, Kuderer N, Agboola O, Balducci L. Evidence-based use of colony-stimulating factors in elderly cancer patients. Cancer Control. 2003;10(6):487-99.

22. Lyman GH, Barron RL, Natoli JL, Miller RM. Systematic review of efficacy of dose-dense versus non-dose-dense chemotherapy in breast cancer, non-Hodgkin lymphoma, and non-small cell lung cancer. Crit Rev Oncol Hematol. 2012;81(3):296-308.

23. Neulasta (pegfilgrastim) for subcutaneous injection. Amgen. 2012. Available at: https://www.accessdata.fda.gov/drugsatfda_docs/ label/2012/125031s0142lbl.pdf. Accessed July 11, 2018.

24. Granix (tbo-filgrastim) for subcutaneous injection. Teva Pharmaceuticals USA. May 2013. Available at: https://www.accessdata.fda.gov/drugsatfda_ docs/label/2013/125294s007lbl.pdf. Accessed July 11, 2018. 


\section{Patient-Administered Biologic and Biosimilar Filgrastim May Offer More Affordable Options for Patients with Nonmyeloid Malignancies Receiving Chemotherapy in the United States: A Budget Impact Analysis from the Payer Perspective}

25. Neupogen (filgrastim) for subcutaneous or intravenous use. Amgen. July 2015. Available at: https://www.accessdata.fda.gov/drugsatfda_docs/ label/2015/103353s5186lbl.pdf. Accessed July 11, 2018.

26. Zarxio (filgrastim-sndz) for subcutaneous or intravenous use. Sandoz. March 2016. Available at: https://www.accessdata.fda.gov/drugsatfda_docs/ label/2016/125553s001lbl.pdf. Accessed July 11, 2018.

27. Holmes FA, O'Shaughnessy JA, Vukelja S, et al. Blinded, randomized, multicenter study to evaluate single administration pegfilgrastim once per cycle versus daily filgrastim as an adjunct to chemotherapy in patients with highrisk stage II or stage III/IV breast cancer. J Clin Oncol. 2002;20(3):727-31.

28. Green MD, Koelbl H, Baselga J, et al. A randomized double-blind multicenter phase III study of fixed-dose single-administration pegfilgrastim versus daily filgrastim in patients receiving myelosuppressive chemotherapy. Ann Oncol. 2003;14(1):29-35.

29. Vose JM, Crump M, Lazarus H, et al. Randomized, multicenter, openlabel study of pegfilgrastim compared with daily filgrastim after chemotherapy for lymphoma. J Clin Oncol. 2003;21(3):514-19.

30. Holmes FA, Jones SE, O'Shaughnessy J, et al. Comparable efficacy and safety profiles of once-per-cycle pegfilgrastim and daily injection filgrastim in chemotherapy-induced neutropenia: a multicenter dose-finding study in women with breast cancer. Ann Oncol. 2002;13(6):903-09.

31. Crawford J, Ozer H, Stoller R, et al. Reduction by granulocyte colonystimulating factor of fever and neutropenia induced by chemotherapy in patients with small-cell lung cancer. New Engl J Med. 1991;325(3):164-70. 32. Trillet-Lenoir V, Green J, Manegold C, et al. Recombinant granulocyte colony stimulating factor reduces the infectious complications of cytotoxic chemotherapy. Eur J Cancer. 1993;29A(3):319-24.

33. Weycker D, Hackett J, Edelsberg JS, Oster G, Glass AG. Are shorter courses of filgrastim prophylaxis associated with increased risk of hospitalization? Ann Pharmacother. 2006;40(3):402-07.

34. Naeim A, Henk HJ, Becker L, et al. Pegfilgrastim prophylaxis is associated with a lower risk of hospitalization of cancer patients than filgrastim prophylaxis: a retrospective United States claims analysis of granulocyte colony-stimulating factors (G-CSF). BMC Cancer. 2013;13:11. Available at: https://www. ncbi.nlm.nih.gov/pmc/articles/PMC3559272/. Accessed July 10, 2018.

35. Weycker D, Malin J, Barron R, Edelsberg J, Kartashov A, Oster G. Comparative effectiveness of filgrastim, pegfilgrastim, and sargramostim as prophylaxis against hospitalization for neutropenic complications in patients with cancer receiving chemotherapy. Am J Clin Oncol. 2012;35(3):267-74. 36. Morrison VA, Wong M, Hershman D, Campos LT, Ding B, Malin J. Observational study of the prevalence of febrile neutropenia in patients who received filgrastim or pegfilgrastim associated with 3-4 week chemotherapy regimens in community oncology practices. J Manag Care Pharm. 2007:13(4):337-48. Available at: https://www.jmcp.org/doi/10.18553/ jmcp.2007.13.4.337.

37. Weycker D, Barron R, Edelsberg J, Kartashov A, Legg J, Glass AG. Risk and consequences of chemotherapy-induced neutropenic complications in patients receiving daily filgrastim: the importance of duration of prophylaxis. BMC Health Serv Res. 2014;14:189.

38. Lubenau H, Sveikata A, Gumbrevicius G, et al. Bioequivalence of two recombinant granulocyte colony-stimulating factor products after subcutaneous injection in healthy volunteers. Int J Clin Pharmacol Ther 2009;47(4):275-82.

39. Lubenau H, Bias P, Maly AK, Siegler KE, Mehltretter K. Pharmacokinetic and pharmacodynamic profile of new biosimilar filgrastim XM02 equivalent to marketed filgrastim Neupogen: single-blind, randomized, crossover trial. BioDrugs. 2009;23(1):43-51.

40. del Giglio A, Eniu A, Ganea-Motan D, Topuzov E, Lubenau H. XM02 is superior to placebo and equivalent to Neupogen in reducing the duration of severe neutropenia and the incidence of febrile neutropenia in cycle 1 in breast cancer patients receiving docetaxel/doxorubicin chemotherapy. BMC Cancer. 2008;8:332.

41. Gatzemeier U, Ciuleanu T, Dediu M, Ganea-Motan E, Lubenau H, del Giglio A. XM02, the first biosimilar G-CSF, is safe and effective in reducing the duration of severe neutropenia and incidence of febrile neutropenia in patients with small cell or non-small cell lung cancer receiving platinumbased chemotherapy. J Thorac Oncol. 2009;4(6):736-40.
42. Engert A, Griskevicius L, Zyuzgin Y, Lubenau H, del Giglio A. XM02, the first granulocyte colony-stimulating factor biosimilar, is safe and effective in reducing the duration of severe neutropenia and incidence of febrile neutropenia in patients with non-Hodgkin lymphoma receiving chemotherapy. Leuk Lymphoma. 2009;50(3):374-79.

43. Schwartzberg LS, Lal LS, Balu S, et al. Clinical outcomes of treatment with filgrastim versus a filgrastim biosimilar and febrile neutropenia-associated costs among patients with nonmyeloid cancer undergoing chemotherapy. J Manag Care Spec Pharm. April 24, 2018 [Epub ahead of print]. Available at: https://www.jmcp.org/doi/pdf/10.18553/jmcp.2018.17447.

44. Douglas AG, Schwab P, Lane D, Kennedy K, Slabaugh SL, Bowe A. A comparison of brand and biosimilar granulocyte-colony stimulating factors for prophylaxis of chemotherapy-induced febrile neutropenia. J Manag Care Spec Pharm. 2017;23(12):1221-26. Available at: https://www.jmcp.org/doi/ pdf/10.18553/jmcp.2017.23.12.1221.

45. Sullivan SD, Mauskopf JA, Augustovski F, et al. Budget impact analysisprinciples of good practice: report of the ISPOR 2012 budget impact analysis Good Practice II Task Force. Value Health. 2014;17(1):5-14.

46. U.S. Census. U.S. and world population clock for July 2013. 2016 Available at: http://www.census.gov/popclock. Accessed July 10, 2018.

47. National Cancer Institute, Surveillance, Epidemiology, and End Results Program. Fast stats. 2016. Available at: http://seer.cancer.gov/faststats/selections.php. Accessed July 10, 2018.

48. Griffiths RI, Barron RL, Gleeson ML, et al. Granulocyte-colony stimulating factor use and medical costs after initial adjuvant chemotherapy in older patients with early-stage breast cancer. Pharmacoeconomics. 2012;30(2):103-18. 49. Culakova E, Thota R, Poniewierski MS, et al. Patterns of chemotherapyassociated toxicity and supportive care in US oncology practice: a nationwide prospective cohort study. Cancer Med. 2014;3(2):434-44.

50. Denduluri N, Patt DA, Wang Y, et al. Dose delays, dose reductions, and relative dose intensity in patients with cancer who received adjuvant or neoadjuvant chemotherapy in community oncology practices. J Natl Compr Canc Netw. 2015;13(11):1383-93.

51. Fine S, Koo M, Gill T, et al. The use of granulocyte colony-stimulating factors in a Canadian outpatient setting. Curr Oncol. 2014;21(2):e229-40. 52. Truven Health Analytics. RED BOOK Online. Micromedex Solutions. Available at: http://www.micromedexsolutions.com. Accessed July 10, 2018. 53. Henry J Kaiser Family Foundation. Employer-sponsored health benefits: 2015 annual survey. 2015. Available at: http://kff.org/report-section/ehbs2015-section-one-cost-of-health-insurance/. Accessed July 10, 2018

54. American Society of Health-System Pharmacists (ASHP). Handbook on Injectable Drugs, 19th ed. Bethesda, MD: American Society of Health-System Pharmacists; 2016.

55. O'Brien S, Radich JP, Abboud CN, et al. Chronic myelogenous leukemia, version 1.2015. J Natl Compr Canc Netw. 2014;12(11):1590-610.

56. Ramsey SD, McCune JS, Blough DK, et al. Colony-stimulating factor prescribing patterns in patients receiving chemotherapy for cancer. Am J Manag Care. 2010;16(9):678-86.

57. Wright JD, Neugut AI, Ananth CV, et al. Deviations from guidelinebased therapy for febrile neutropenia in cancer patients and their effect on outcomes. JAMA Intern Med. 2013;173(7):559-68.

58. Lyman GH, Kuderer NM, Crawford J, et al. Predicting individual risk of neutropenic complications in patients receiving cancer chemotherapy. Cancer. 2011;117(9):1917-27.

59. Klastersky J, Awada A, Aoun M, Paesmans M. Should the indications for the use of myeloid growth factors for the prevention of febrile neutropenia in cancer patients be extended? Curr Opin Oncol. 2009;21(4):297-302.

60. Cosler LE, Eldar-Lissai A, Culakova E, et al. Therapeutic use of granulocyte colony-stimulating factors for established febrile neutropenia: effect on costs from a hospital perspective. Pharmacoeconomics. 2007;25(4):343-51. 61. Crawford J, Dale DC, Kuderer NM, et al. Risk and timing of neutropenic events in adult cancer patients receiving chemotherapy: the results of a prospective nationwide study of oncology practice. J Natl Compr Canc Netw. 2008;6(2):109-18. 